\title{
RESENHA CRÍTICA: TRAJETÓRIAS DE PESQUISAS DA REDE “MOVER"i
}

\author{
Pedro José Santos Carneiro Cruz
}

\begin{abstract}
Resumo: As trajetórias de pesquisas realizadas pelo Grupo de Pesquisa "Educação Intercultural Movimentos Sociais" (CNPq/UFSC), conhecido como núcleo ou rede "Mover", são aqui analisadas sob a perspectiva da extensão universitária popular, entendida como mergulho permanente, sistemático e profundo na realidade social. Neste sentido, a experiência do "Mover" aparece como um processo intenso de comunicação dialógica e engajada com os movimentos populares que enseja, reciprocamente, o empoderamento dos movimentos populares como protagonistas de sua "práxis" e a construção social permanente da universidade popular.
\end{abstract}

Palavras chaves: Educação Intercultural; Movimentos Sociais; Extensão universitária.

\section{REVIEW: “MOVE” NETWORK RESEARCH TRAJECTORIES}

\begin{abstract}
The research trajectories of the Research Group "Intercultural Education Social Movements" (CNPq / UFSC), known as the "Move" nucleus or network, are analyzed here from the perspective of the popular university extension, understood as permanent, systematic and deep diving in the social reality. In this sense, the "Move" experience appears as an intense process of dialogic and engaged communication with the popular movements, that reciprocally provokes the empowerment of popular movements as protagonists of their "praxis" and the permanent social construction of the popular university.
\end{abstract}

Keywords: Intercultural Education; Social Movements; University Extension.

A construção compartilhada do conhecimento na interface universidade e movimentos sociais é possível. É isso o que Reinaldo Matias Fleuri e a experiência do Núcleo Mover nos ensinam na obra "Educação intercultural e movimentos sociais: trajetórias de pesquisas da Rede Mover".

A Universidade tem se constituído, paulatina e cotidianamente, em um espaço profícuo, frutífero e mobilizador de experiências e práticas sociais direcionadas à construção de referências éticas, políticas e pedagógicas para a sociabilidade, as relações humanas, a ação 
das políticas públicas e as realizações formativas. Esse processo vem decorrendo há muitas décadas e em diferentes contextos sociais, políticos e culturais. As paredes da instituição acadêmica (em sua maioria frias, sem vida e assépticas), sua dominante característica de autoritarismo e o descompromisso com os sofrimentos e explorações humanas, sendo todos redirecionados para um novo agir profissional, científico e social.

Há muito tempo, e ainda nos dias de hoje, no seio da própria academia muitas vezes brotaram sementes de mudanças, particularmente pela ousadia, compromisso e dedicação de diferentes sujeitos no delineamento e aprimoramento de ações de extensão, de pesquisa ou de ensino com bases éticas e caminhos metodológicos humanizantes, demonstrando, de maneira concreta, que a pauta da universidade e de suas realizações poderia efetivamente ser outra, distinta da dominante. Uma marcha em outra direção.

Historicamente, estudantes, professores, técnicos-administrativos e membros de movimentos sociais e práticas populares vêm reinventando o fazer universitário tanto através da denúncia do que oprime, incomoda e submete, quanto através do anúncio criativo de novas possibilidades, através de ações concretas. Outra relação humana se dá, estabelecem-se métodos, técnicas e procedimentos coerentes com um fazer universitário irremediavelmente compromissado com a emancipação social, humana e política, sobretudo das pessoas e grupos em situação de exclusão, opressão, perseguição, sofrimento, dor, pobreza e/ou miséria. O objetivo é aliar-se às classes populares, seus grupos e protagonistas, desvelando processos educacionais capazes de subsidiar, fomentar, aprimorar e qualificar o enfrentamento, a contestação e a contraproposição.

Tudo isso para constituir práticas acadêmicas de pesquisa e de extensão, bem como para formar profissionais, na linha de um enfrentamento contundente e sistemático não apenas dos sintomas dos problemas sociais, mas de suas raízes mais profundas. Por isso, uma universidade preocupada em superar, o mais permanente e estruturalmente possível, as principais situações-limite, obstáculos e lacunas da vida em sociedade, na perspectiva de contribuir com o estabelecimento (dinâmico e em meio a contradições) de um horizonte de uma sociedade politicamente igualitária, socialmente solidária, economicamente justa e culturalmente diversa, onde a pauta seja o apoio incondicional à realização dos projetos de felicidades das pessoas e a promoção do outro e da outra. 


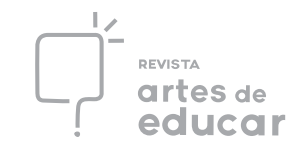

Reinaldo Fleuri é um dos principais protagonistas do campo educacional brasileiro, em especial no que tange a conhecimentos, reflexões e metodologias direcionadas a construção de uma universidade que, conforme exposto anteriormente, tenha no diálogo com os movimentos sociais uma prática cotidiana, autentica e expressadora de um cristalino compromisso social, refletido em um posicionamento ético e político a favor daqueles e daquelas humanamente explorados(as) e socialmente excluídos(as).

$\mathrm{Na}$ obra "Educação Intercultural e Movimentos Sociais - trajetórias de pesquisas da Rede Mover", podemos conhecer um pouco da rica história de construção educacional de Reinaldo Fleuri e de seus trabalhos nesse campo, os quais traduzem um percurso potente na construção de reflexões, na explicitação de ideias e na provocação de debates críticos no sentido de pensarmos o contexto universitário dominante, problematizarmos suas contradições e vislumbrarmos caminhos possíveis para constituição de outros horizontes para a vida e a prática acadêmica. E tal percurso não se deu de forma isolada e individualista.

A leitura nos permite compreender com clareza que a obra escrita por Fleuri é, em verdade, uma expressão dos esforços e dedicações de uma série diversa de atores do campo acadêmico e dos movimentos sociais e populares. De construções de experiências concretas onde se buscou tanto elaborar, como exercitar metodologias, abordagens e perspectivas para o fazer universitário, particularmente tendo, como dissemos anteriormente, a Extensão como ponto de partida. Em sendo ponto de partida, Fleuri e seus companheiros empreenderam também atividades de pesquisa e investigação em nível de graduação e pós-graduação, e também promoveram inserções desses debates, lógicas e espaços na graduação e na formação profissional.

O Núcleo "Mover" foi criado em 1994 por um grupo de professores e estudantes do Programa de Pós-Graduação em Educação da Universidade Federal de Santa Catarina para articular suas pesquisas relativas à relação entre Universidade e Movimentos Sociais. Em 1997, redefiniu seu enfoque, numa perspectiva de educação popular, para "Educação Intercultural e Movimentos Sociais" e com este enfoque foi registrado no Diretório de Grupos de Pesquisa do CNPqiii. Desde 2011 articulou-se com o PPGICH/UFSC e por quatro anos (2012-2016) cooperou estreitamente com o Instituto Federal Catarinense. 
O Mover desenvolveu pesquisas articuladas com intervenção educativa, nos projetos de Formação de Educadores Populares de Capoeira (UFSC, 2004, 2005 e 2007), de Curso de Formação de Professores para a Educação Inclusiva (SESISC, 2007 e 2008), de Curso de Formação de Professores para a Diversidade e Cidadania (MEC/UAB, 2009) e de produção de material didático para o trabalho com Diversidade Religiosa e Direitos Humanos em âmbito nacional (MEC, 2010-2013). Além da formação de pesquisadores (em nível de iniciação científica, mestrado, doutorado e pós-doutorado) e de ampla produção acadêmica, o Grupo de pesquisa promoveu significativo processo de cooperação científica interinstitucional e internacional. Liderou quatro congressos internacionais $(1997,2003,2006,2009)$ e organizou várias publicações conjuntas internacionais.

Em uma experiência rica como essa, observa-se concretamente o saber da extensão e os caminhos nela desvelados sendo úteis e reorientadores para a constituição de práticas de ensino e de pesquisa socialmente úteis e articuladas com a mobilização de conhecimentos emancipadores.

O livro apresenta, analisa e aponta caminhos de uma universidade para a qual o conhecimento é tanto mobilizador, como também não é propriedade exclusiva sua. Um conhecimento mobilizador porque constitui-se como parte de um processo longo, dinâmico e desafiador de dedicação de pessoas em considerar criticamente a realidade para debruçar sobre problemas e, então, buscar coletiva e dialogalmente estratégias para a superação dos mesmos. Um conhecimento eminentemente mergulhado no mundo concreto e compromissado em subsidiar a ação de sujeitos para a superação dos problemas e contradições. Um conhecimento que, fundamentalmente, não provém e nem se detém aos entes acadêmicos, mas reconhece que seu desenvolvimento pode, e deve, se dar em interfaces e conflitos de saberes populares e científicos - saberes da vida.

Destaca-se da obra, também, o entendimento contundente de que, no âmbito acadêmico, a Extensão universitária tem sido um dos espaços mais significativos para a experimentação, o desenvolvimento e o aprimoramento dessas outras bases para a educação superior e a construção de conhecimentos. Por meio dela, diversos sujeitos vêm empreendendo práticas coletivas e constituindo comunidades de trabalho em uma comunicação cotidiana e transformadora entre estudantes, professores, técnicos e sujeitos de 
comunidades, movimentos, práticas populares e outras entidades e organizações da sociedade civil.

Por isso é que temos defendido enfaticamente que a Extensão deve ser o ponto de partida para um agir social, profissional e técnico que seja crítico, emancipador e construído compartilhadamente pelo diálogo. Com isso, não pretendemos referir exclusivamente os projetos e programas institucionais de extensão como esse lugar privilegiado de ponto de partida. Estamos referindo-nos à Extensão como mergulho na realidade social, como comunicação (na acepção de Paulo Freire) e como trabalho social (na acepção de José Francisco de Melo Neto). Sendo assim um ponto de partida que pode se dar em atividades de campo de pesquisas, em estágios curriculares, em atividades práticas de disciplinas. Ou seja, em espaços acadêmicos (seja de ensino, extensão ou pesquisa), nos quais se propicie um mergulho permanente, sistemático e profundo na realidade social, suas contradições, processos, dinâmicas e desafios. Um mergulho permeado por espaços e vivências de comunicação entre pessoas, seus contextos, saberes da vida, interesses e culturas. Um mergulho pautado pela construção de trabalho sociais concretos. Vai se constituindo, dessa forma, uma perspectiva de conversidade, conforme fundamenta Reinaldo Fleuri, na direção da conformação e aprimoramento de um conhecimento conversitário.

Nas palavras do próprio Fleuriv ${ }^{i v}$ o sentido da conversidade implica

reconhecer os múltiplos movimentos sociais como sujeitos produtores e interlocutores de conhecimento científico, [o que] é uma decisão que pode nos abrir a formas mais críticas, criativas e sócio-ecológicamente eficazes de se conceber e de se produzir ciência no mundo contemporâneo. É o campo fecundo do que estamos chamando de conhecimento conversitário e que emerge no campo do que Boaventura de Sousa Santos chama de conhecimento pluriversitário (p.42).

Para todas as pessoas que buscam se debruçar na extensão como ponto de partida e na perspectiva freireana e educativo popular da universidade é condição sine qua non que, em suas produções e construções, haja diálogo com os movimentos sociais populares e as práticas comunitárias. É isso que Fleuri e a experiência do Mover ensinam. A comunicação dos entes universitários com o mundo concreto e seus sujeitos é condição fundante nessa experiência, e 
os saberes e conhecimentos produzidos foram sistematizados em uma relação de vínculo, companheirismo, presença sistemática e diálogo autentico.

O Mover e suas experiências não usam os movimentos sociais populares e as práticas comunitárias apenas em seus discursos, como forma de torná-los esteticamente atraentes, ao contrário de como fazem muitos grupos e intelectuais da linha educacional progressista. Toda obra é construção compartilhada e não fonte da iluminação individual de qualquer intelectual que seja.

Em nosso entendimento, as palavras contidas nessa obra colaboram no sentido de fazer da Extensão em Educação Popular - e sua articulação com a pesquisa e com o ensino um processo de luta e de construção social permanente na perspectiva de propormos uma outra universidade. Uma universidade popular. Popular não principalmente por seu público, mas por sua intencionalidade ética e política, qual seja a emancipação social, humana e política em direção de horizontes de felicidade, humanização, solidariedade, equidade e justiça na sociedade.

\footnotetext{
${ }^{\mathrm{i}}$ Obra: FLEURI, Reinaldo Matias. Educação intercultural e movimentos sociais: trajetórias de pesquisas da Rede Mover. João Pessoa: Editora do Centro de Comunicação, Turismo e Artes da Universidade Federal da Paraíba (CCTA/UFPB), 2017.

ii Professor do Departamento de Promoção da Saúde do Centro de Ciências Médicas da Universidade Federal da Paraíba (UFPB). Contato: pedrojosecruzpb@yahoo.com.br. O presente texto foi construído considerando como base na apresentação, de minha autoria, para o livro "Educação Intercultural e Movimentos Sociais", da Editora do CCTA, 2017, de Reinaldo Matias Fleuri.

iii http://www.dgp.cnpq.br/dgp/espelhogrupo/1160319095731057

iv FLEURI, Reinaldo Matias. Conversidade: conhecimento construído na relação entre educação popular e universidade. REUNIÃO ANUAL DA ANPED, 27, 2004. Sociedade, Democracia e Educação: Qual universidade? Caxambu, ANPEd, 2004.
} 